\title{
The effects of conditioning stimuli on the F-response
}

\author{
FL MASTAGLIA, WM CARROLL \\ From the Department of Neurology and University Department of Medicine, Queen Elizabeth II Medical \\ Centre, Perth, Western Australia, Australia
}

SUMMARY The effect of conditioning stimuli on the F-response was investigated in normal subjects using stimulus pairs with interstimulus intervals of 1 to $400 \mathrm{~ms}$. The "recovery curve" for the F-response was found to be similar to that for the $\mathrm{H}$-reflex but differences were found between male and female subjects. The significance of these findings is discussed.

The $\mathrm{F}$ response is a late muscle response thought to result from retrograde activation of motor neurons following peripheral stimulation of their axons. ${ }^{1-4}$ It has received attention largely as a means of assessing conduction in the proximal segment of the motor neurons. ${ }^{5-11}$ In addition it has been suggested that the size and frequency of $F$ responses during a period of stimulation are indices of motor neuron excitability. ${ }^{12}$ Although Magladery et al ${ }^{13}$ considered that the $F$ response was not altered by shocks preceding the test stimulus by $30-80 \mathrm{~ms}$, subsequent observations have shown that the $F$ response may in fact be depressed by conditioning stimuli. ${ }^{1415}$ However, there has been no systematic study of the effects of conditioning stimuli on the $F$ response.

We have studied the effects of conditioning stimuli on $F$ response numbers and amplitudes in healthy males and females and have constructed a "recovery curve" comparable to that which has been used more widely for the $\mathrm{H}$ reflex.

\section{Subjects and methods}

Nine subjects (five males and four females, 25 to 41 years of age) were studied. None had symptoms of median nerve dysfunction and in all motor and sensory nerve conduction was normal. F responses were recorded from the abductor pollicis brevis muscle of the dominant upper limb using gold disc electrodes placed over the motor point of the muscle and metacarpophalangeal joint of the thumb during stimulation of the median nerve at the wrist (cathode proximal). Stimuli were $\mathbf{0 \cdot 1} \mathrm{ms}$ square wave electrical pulses $25 \%$ supramaximal for the $M$ response. The subject

Address for reprint requests: Professor FL Mastaglia, University Department of Medicine, Queen Elizabeth II Medical Centre, Nedlands, WA 6009, Australia.

Received 12 June 1984

Accepted 21 July 1984 was recumbent in a noise-free room with dimmed lights and was allowed to relax in this position for a period of 10-15 minutes before commencement of stimulation. The ambient room temperature was maintained between 23 and $35^{\circ} \mathrm{C}$.

The subsequent procedure was as follows:

(i) A sequence of 50 single stimuli were delivered at a rate of $1 \mathrm{~Hz}$.

(ii) Paired stimuli at interstimulus intervals ranging fron $1 \mathrm{~ms}$ to $400 \mathrm{~ms}$ were then delivered at a rate of $0 . \$$ $\mathrm{Hz}$; 50 consecutive pairs of stimuli were given at each interstimulus interval with an interval of 2 minute between each stimulus sequence.

(iii) A final sequence of 50 single stimuli were given at 8 rate of $1 \mathrm{~Hz}$.

Responses were displayed on the cathode-ray oscillo scope screen of a Medelec MS6 electromyograph and were photographed using a fibre optic recording system? Records were subsequently analysed and the following parameters were derived:

(i) The numbers and mean peak-to-peak amplitude of $F$ responses recorded during the initial and final single stimulus sequences.

(ii) For each interstimulus interval, the number and mean peak-to-peak amplitude of $F$ responses elicited by the test stimulus (F2), as well as the total amplitude of all F2 responses recorded at each interstimulus interval. Responses elicited by the conditioning and test stimuli could only be reliably distinguished with inter-stimulus intervals greater than $2 \mathrm{~ms}$.

\section{Results}

The mean $\mathrm{F}$ response latencies in the nine subjects ranged from $26.9 \mathrm{~ms}$ to $31.2 \mathrm{~ms}$. Plots of F2 response numbers at increasing interstimulus intervals in each of the nine subjects are shown in fig 1 and 2 . It will be seen that in each subject there was a period of variable duration following the conditioning stimulus during which F2 numbers and amplitudes were reduced. In both males and females, 


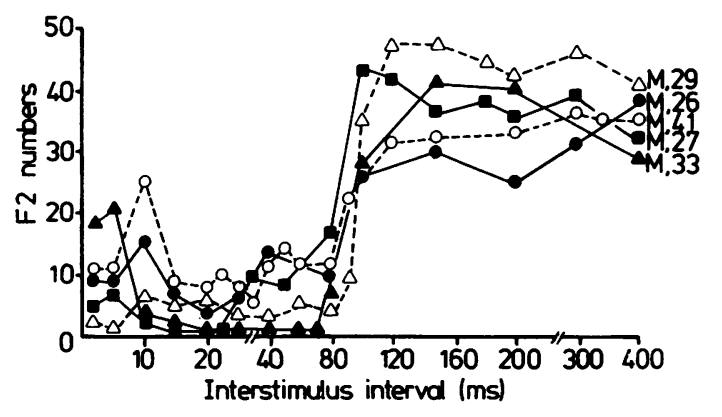

Fig 1 F-response recovery curves for 5 normal male subjects aged 26-41 years. The curves show the numbers of responses elicited by a series of 50 consecutive test stimuli plotted against the interstimulus interval.

the F2 numbers curve showed an initial depression in the first $5 \mathrm{~ms}$, usually followed by an increase in numbers between 5-10 ms, and a further decline between $10-15 \mathrm{~ms}$. In the males, there was a subsequent period of depression up to $60-80 \mathrm{~ms}$, whereas in the females, this was only present up to 25-30 ms. The later parts of the curves were again variable in different subjects. In six subjects (four males and two females) there was a period of facilitation from $80 \mathrm{~ms}$ to about $300 \mathrm{~ms}$ during which F2 numbers were greater than the numbers of responses initially recorded with the single stimulus sequence, while in one female subject, a period of partial depression in $\mathrm{F} 2$ numbers persisted up to 400 ms. The curves for mean and total F2 response amplitude (fig 3) showed similar trends to the F2 number curves in most subjects but there was a greater degree of inter-individual variability. In most subjects the mean and total F2 amplitude curves were very similar (for example fig 3 ) and in general the total F2 amplitude curve corresponded closely to the curve for $F 2$ response numbers in individual subjects.

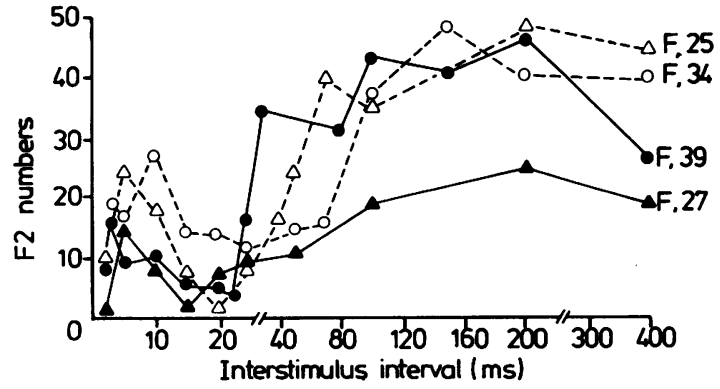

Fig 2 F-response recovery curves in 4 normal female subjects aged 25-39 years. Other details as in fig 1 .

\section{Discussion}

The "recovery curve" for the $F$ response is similar to that previously reported for the $\mathrm{H}$ reflex. ${ }^{1617}$ As in the case of the $\mathrm{H}$ reflex, there is depression of the test response in the first $5 \mathrm{~ms}$ after the conditioning stimulus, which is most likely to be due to refractoriness of motor axons after the conditioning volley. ${ }^{18}$ An additional factor to be considered is the possibility of collision between the descending volley resulting from antidromic firing of motoneurons by the conditioning stimulus and the ascending volley set up by the test stimulus. This could occur with interstimulus intervals of up to $35 \mathrm{~ms}$, this being a reasonable estimate of the maximal afferent, turnaround and efferent conduction time for the $F$ response, and could account at least in part for the depression in $\mathrm{F} 2$ responses at these interstimulus intervals. However, it is likely that depression of motoneuron excitability due to presynaptic inhibition of $1 \mathrm{~A}$ afferents ${ }^{19}$ and to recurrent (Renshaw cell) inhibition ${ }^{2021}$ is also partly responsible for the depression of test responses in the first $35 \mathrm{~ms}$ after the conditioning stimulus and for the longer-lasting depression found up to $80 \mathrm{~ms}$ after the conditioning stimulus in males. The facilitation found in a number of subjects from 80 to $300 \mathrm{~ms}$ is similar to that which occurs with the $\mathrm{H}$ reflex ${ }^{1617}$ and has been attributed to the effects of spindle afferent discharges during muscle relaxation. ${ }^{22}{ }^{23}$ The possible involvement of segmental spinal interneuronal circuits and of supraspinal mechanisms also need to be considered. ${ }^{24}$

The technique described provides an alternative to the $\mathrm{H}$ reflex for studying the excitability and refractory properties of the motoneuron pool. However, it has two main limitations. First, because of the refractory period of peripheral axons and the problem of "collision" referred to above, the first

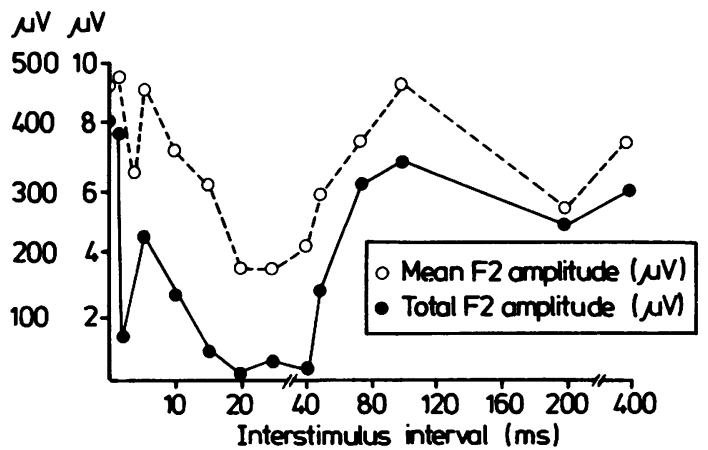

Fig 3 Plots of the mean and total amplitude of responses elicited by a series of 50 consecutive test stimuli at different intervals in a normal male subject. 
25-35 ms of the curve does not necessarily reflect changes in excitability of the motoneurons themselves. Secondly, because only a relatively small proportion of motor units contribute to individual $F$ responses, the technique does not assess the properties of the whole motoneuron pool. Nevertheless, it may be useful for evaluating the duration of depression and the time course of late facilitation after conditioning stimuli, particularly in large motoneurons which are thought to be preferentially activated in $\mathrm{F}$ responses. ${ }^{4}$

The differences in the recovery curve in males and females are of interest and to our knowledge have not previously been reported. The basis for these differences is uncertain and warrants further investigation.

\section{References}

' Magladery JW, McDougall DB. Electrophysiological studies of nerve and reflex activity in normal man: I. Identification of certain reflexes in the electromyogram and the conduction velocity of peripheral nerve fibers. Bull Johns Hopkins Hosp 1950;86:265-90.

${ }^{2}$ McLeod JG, Wray SH. An experimental study of the F wave in the baboon. $J$ Neurol Neurosurg Psychiatry 1966;29:196-200.

${ }^{3}$ Mayer RF, Feldman RG. Observations on the nature of the $F$ wave in man. Neurology (Minneap) 1967; 17:147-56.

${ }^{4}$ Fisher MA. Physiology and clinical use of the F response. American Association of Electromyography and Electrodiagnosis, Minimonograph No. 13, 1980;pp1-11.

${ }^{s}$ Kimura J. F-wave velocity in the central segment of the median and ulnar nerves: a study in normal subjects and in patients with Charcot-Marie-Tooth disease. Neurology (Minneap) 1974;24:539-46.

${ }^{6}$ Kimura J. Proximal versus distal slowing of motor nerve conduction velocity in the Guillain-Barré syndrome. Ann Neurol 1978;3:344-50.

${ }^{7}$ Kimura J, Butzer JF. F-wave conduction velocity in Guillain-Barré syndrome. Arch Neurol 1975;32: 524-9.

${ }^{8}$ Albizzati MG, Bassi S, Basserini D, Crespi V. F-wave velocity in motor neurone disease. Acta Neurol Scan 1976;54:269-77.

${ }^{9}$ King D, Ashby P. Conduction velocity in the proximal segments of a motor nerve in the Guillain-Barré syndrome. J Neurol Neurosurg Psychiatry 1976;39:53844.
${ }^{10}$ Eisen A, Schomer D, Melmed C. The application of $\underline{\underline{ }}$ $F$-wave measurements in the differentiation of proxi- $Z$ mal and distal upper limb entrapments. Neurology (Minneap) 1977;27:662-8.

"Panayiotopoulos CP, Scarpalezos S, Nastas PE. F-wave $\stackrel{\mathscr{C}}{\leftrightarrows}$

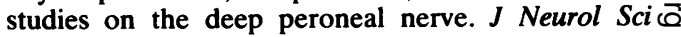
1977;31:319-29.

12 Eisen A, Odusote K. Amplitude of the F wave: a potential means of documenting spasticity. Neurology $\stackrel{\rho}{\underline{n}}$ (Minneap) 1979;29:1306-9.

${ }^{13}$ Magladery JW, Porter WE, Park AM, et al. Electrophysiological studies of nerve and reflex activity in normal man. IV. The two-neurons reflex and $\overrightarrow{\vec{D}}$ identification of certain action potentials from spinal 0 roots and cord. Bull Johns Hopkins Hosp $\frac{\bar{\sigma}}{2}$ 1951;88:479-519.

14 Thorne J. Central responses to electrical activation of $\frac{\vec{\Phi}}{\mathscr{D}}$ the peripheral nerves supplying the intrinsic hand $\varrho$ muscles. J Neurol Neurosurg Psychiatry 1965; ڤ

28:482-95.
${ }^{15}$ Fra L, Brignolio F. F and $H$ responses elicited from $\vec{\circ}$ muscles of the lower limb in normal subjects. J Neurol $\overrightarrow{\vec{\omega}}$ Sci 1968;7:251-61.

${ }^{16} \mathrm{McLeod}$ JG. $\mathrm{H}$ reflex studies in patients with cerebellar disorders. J Neurol Neurosurg Psychiatry 1969; 32:21-7.

${ }^{17}$ Crayton JW, Rued RR. An oscillatory component of the H-reflex. J Neurol Neurosurg Psychiatry 1980j 43:239-42.

${ }^{18}$ Fukushima Y, Yamashita N, Shimada Y. Facilitation क्षf H-reflex by homonymous la-afferent fibers in man Neurophysiology 1982;48:1079-88.

${ }^{19}$ Eccles JC. Presynaptic inhibition in the spinal cord. IF: T Eccles JC, Schade JP, eds. "Physiology of Spinal Neurons", Progress in Brain Research, Vol. 12, Anf terdam, Elsevier 1964;65-89.

${ }^{20}$ Veale JL, Rees S. Renshaw cell activity in man.J Neur Neurosurg Psychiatry 1973;36:674-83.

${ }^{21}$ Hultborn H, Pierrot-Deseilligny E. Changes in recurrent. inhibition during voluntary soleus contractions in man $\square$ studied by an H-reflex technique. J Physiol (London) 1979;297:229-51.

${ }^{22}$ Granit R, Kellerth JO, Szumski AJ. Intracellular autogenetic effects of muscular contraction on extensor motoneurones; the silent period. J Physiol (London) 1966;182:484-503.

${ }^{23}$ McLeod JG, Van der Muelen JP. Effect of cerebellar 3 ablation on the $\mathrm{H}$ reflex in the cat. Arch Neurol? 1967; 16:421-32.

24 Delwaide PJ, Crenna P, Fleron MH. Cutaneous nerve stimulation and motoneuronal excitability: I. Soleus, tibialis anterior excitability after ipsilateral and con-? tralateral sural nerve stimulation. J Neurol Neurosurg음 Psychiatry 1981;44:699-707. 